\title{
The Rise of Rapid Prototyping in a Biomedical Engineering Design Sequence
}

\section{Prof. Joe Tranquillo, Bucknell University}

Dr. Joseph (Joe) Tranquillo is an Associate Professor at Bucknell University in the Department of Biomedical Engineering, He is also co-director of the Institute for Leadership in Technology and Management, co-director of the KEEN Winter Interdisciplinary Design Program, and chair of the Biomedical Engineering Division of ASEE. Tranquillo has published three undergraduate textbooks and numerous engineering education publications, and has presented internationally on engineering and education. His work has been featured on the Discovery Channel, CNN Heath and TEDx. He was a US Case Professor of the Year nominee and a National Academy of Engineering Frontiers of Engineering Education faculty member.

\section{Ms. Annmarie Mullen, Bucknell University}

Annmarie is a senior biomedical engineering major at Bucknell University. She has been involved in various program on campus that aim to merge entrepreneurship and engineering including KEEN IDEAS courses, Bucknell Fabrication and Design (BFAB), KEEN Winter Disciplinary Design Experience, and the Bucknell Institute for Leadership in Technology and Management. Most recently, she has co-founded Bucknell's Chapter of EMpwr, a KEEN student lead organization focused on bringing the entrepreneurial mindset to engineering education. 


\section{The rise of rapid prototyping in a biomedical engineering design sequence}

\section{Introduction}

Prototyping has always played an important role in the design process as way to determine conceptual viability and iterate upon an idea. Over the last decade, the decreasing costs, improved accuracy, and wide-spread availability of rapid prototyping (RP) technology has lowered the barriers to early-stage prototyping. At universities, the result has been the rise of maker's spaces, skill-based pop-up classes and rapid design challenges. In this paper, we explore the history of rapid prototyping throughout the 1990's and 2000's, and use a case study from a specific biomedical engineering capstone sequence to illustrate how the availability of rapid prototyping has impacted capstone projects and biomedical engineering education at the undergraduate level.

\section{The Early History of Rapid Prototyping}

Rapid prototyping (RP) is the process by which a computer-aided design (CAD) file is used to control an automated technology in order to produce a physical model. ${ }^{1}$ Its origin is often cited to be with the release of the first technology by 3D Systems in 1987 and it was primarily used to create a first generation prototype to quickly verify a design. ${ }^{1}$ The first commercialized technologies in the 1990's were based upon addition or removal of liquids, powders or solids (Table 1). Liquid-based RP involves the "solidification of a resin on contact with a laser, the solidification of an electrosetting fluid, or the melting and subsequent solidification of the prototype material". 2 Specific technologies include stereolithography, fluid deposition modeling, and ink jet printing. ${ }^{3}$ For powder based RP, the powders are compounded with "a laser or by the selective application of binding agents" and technologies include selective laser sintering, gas phase deposition, ${ }^{2}$ and powder/laser based 3D printing. ${ }^{3}$ Solids are bound together with a laser or an adhesive ${ }^{2}$, for example in laminated object manufacturing. ${ }^{3}$ Additive manufacturing was used to make prototypes that "reproduce functions that require strength," concept models that check the geometry, functional parts that are using in tool making such as molds and dies, and medical models including pre-operative physical models and prostheses. ${ }^{3}$

The medical industry was one of the early adopters of RP through "surgical planning and realization,"5 (i.e. visualizing and planning out a surgery before performing it using rapid prototypes of organs and implants). One of the earliest uses was in CMF (Craniomaxillofacial) surgery where there "are congenital, system-bound growth disorders, facial craniosynostoses... and other congenital skull and face dysplasia." $"$ The complexity and high variability of the presentation of the disorders require patient specific treatments. Rapid prototypes of the facial structure, made using the patient's scans, have allowed surgeons to select the best technical 
approach in advance of the surgery. This results in decreased OR time, and money spent, as well as better education of the patient. ${ }^{5}$

Table 1 Development of material addition RP technologies in the 1980's-1990's ${ }^{4}$

\begin{tabular}{|c|c|}
\hline Name & $\begin{array}{c}\text { Development } \\
\text { years }\end{array}$ \\
\hline Stereolithography (SLA) & $1986-1988$ \\
\hline Solid Ground Curing (SGC) & $1986-1999$ \\
\hline Laminated Object Manufacturing (LOM) & $1985-1991$ \\
\hline Fused Deposition Modeling (FDM) & $1988-1991$ \\
\hline Selective Laser Sintering (SLS) & $1987-1992$ \\
\hline 3D Printing (3DP) & $1985-1997$ \\
\hline
\end{tabular}

Despite the promise, RP was not commonly utilized in industry or academia throughout the 1990 's due to limited accuracy and cost. ${ }^{6}$ While rapid prototypes were supposed to be functional, their accuracy was often so poor that they were considered "a greater handicap than strength". 3 Furthermore, due to the high price tag, they were "not yet easy to cost-justify."6

\section{Rapid Prototyping Today}

RP today has grown immensely since the 1990's, due to the optimization of speed and accuracy, falling costs, and new technologies. Material removal technologies expanded beyond milling and routing to include laser, water-jet, and plasma cutting. All of these new cutting practices use a computer controlled process can cut in a 2D plane. Plasma cutting, routing, and milling, however, can also cut 3D parts using a five axis system. Additive processes have also advanced to include jetting systems, direct metal laser sintering, and 3D printing. These different technologies use everything from UV lamps to cure a liquid resin, to extruders that melt and layer polymers on a build plate. Likewise the list of usable materials has grown to include metals, additional plastics, paper, ceramics, and more. ${ }^{7}$

In industry, RP is "proving vital in cost and time-savings for the development process." 8 
Prototypes that previously required many hours of time from a trained machinist, often on high end mills or lathes, can now be accomplished in less time with less experience. A product's timeto-market is greatly decreased by creating RP proof-of-concepts faster and for less cost. Occasionally, rapid prototyped parts are even used in final products, which can further lower costs. ${ }^{8}$

Universities were early adopters of RP in the 1990's, but primarily as novelty technologies that were only used by select individuals or groups. The early 2000's saw universities investing in RP machines that cost upwards of $\$ 100,000$ but they were generally reserved for specific courses and students. ${ }^{9}$ Due to a reduction in cost over the past decade, RP has diffused very broadly into the academic world, and in particular into undergraduate design education. RP technologies generally do not require a machinist's knowledge and technical expertise, which has brought the manufacturing experience closer to the students; with minimal training students can quickly manufacture a functional device themselves and begin to iterate on the design. To supplement design within the curriculum, many programs have also added more formal training in RP, either in the design classes or by adding entire courses based on CAD and prototyping., ${ }^{9,11,12}$

\section{Manufacturing and Rapid Prototyping at Bucknell University}

In the remainder of this paper, we will highlight a particular biomedical engineering program and how rapid prototyping has entered into the curriculum, specifically the senior capstone, over the past decade. For context, until the 2000's, most prototyping at Bucknell was done in the Project Development Lab (PDL), on mills, lathes, and grinding machines. All machining was done by PDL technicians, and as such, jobs were constrained by the schedule of the PDL and workload of the technicians. In some rare cases, a student may have been approved to work on certain machines under supervision, but again they were often constrained by the schedule of the PDL. Furthermore as students had only a theoretical knowledge of machining practices, their designs often had to be changed, leading to an even greater demand on the technicians. The PDL slowly began to acquire RP technologies throughout the 2000's, for example a CNC router, but their use was still restricted due to training and cost. The equipment was thus reserved for only a select few projects that could not be done another way, and primarily only in senior design classes (Thomas Thul, personal communication, July 30, 2016). The atmosphere began to completely change in the later 2000's and 2010's, as the PDL acquired less expensive equipment that required less training. The trend continued, as it has on university campuses around the world, outside of the PDL in the form of maker's spaces that have open access, training programs and student leaders. Many capstone projects now turn to these alternative spaces for rapid prototyping, greatly increasing both accessibility and the iteration cycle on their design. ${ }^{13}$

\section{Biomedical Engineering at Bucknell University}


The curriculum and pedagogy in the Biomedical Engineering Department at Bucknell University has adapted in response to the rise in rapid prototyping. BME majors have semester-long projects in many of their classes leading up to senior design. For example, final projects in Fundamentals of Biomedical Engineering, Bioinstrumentation, and Fundamentals of Biomedical Signals and Systems, often incorporate rapid prototyped parts. A Fabrication and Experimental Design (BMEG 409) course focuses on fabrication and material selection, biocompatibility, computer-aided design, and documentation.

The Senior Capstone Sequence (BMEG 401 and 402) builds upon these experiences with rapid prototyping. Briefly, students spend the first two months (BMEG 401) finding clinical problems by shadowing physicians at a local hospital, and then narrow that list of problems to one that will become their capstone project. At the end of the sequence (BMEG 402), each team is required to present a functional prototype that addresses the real clinical problem they identified. Over the past decade, the content, coursework, and outcomes of the capstone projects have changed. It was the goal of this study to determine how these changes have been initiated by the availability of RP

\section{Methods}

The ten years' of senior design projects (2007-2016) were analyzed to determine the trends and changes in the senior design process and projects. The final design reports from all 43 teams (2-5 students per team), were read. The latest reports (2016), were read first followed by those from the program's first year (2007), in order to determine the types and range of changes that have evolved over time. Rapid Prototyping was determined to be one of the critical change variables. The remainder of the reports were then read and analyzed in chronological order.

Many RP changes emerged throughout the course sequence's history including the method of manufacturing prototypes, the use of a failure modes evaluation and analysis (FMEA) on the proposed device, etc. With regard to manufacturing methods, student teams chose either traditional manufacturing methods or RP methods. Manufacturing methods required the use of mills, lathes, etc., while RP involved technologies used CNC routers, 3D printers, or laser cutters. The amount of RP that a group used in their project varied from using it once early in the design process to having the entire final device rapid prototyped. For this reason, a four point scoring system was developed to describe the extent of RP used by a team (Table 2). Zero (0) indicated that a group never used RP in any capacity; everything in their process and final product were either purchased or machined. A ranking of little use (scored as 1) was given to groups that used RP methods to test a concept needed for their project but these parts were not ultimately used in their prototype. Medium use (scored as 2) was assigned to groups that used RP as a stepping stone to make their prototype, such as a mold or a preliminary model. Finally, a project was given a heavy use (scored as 3 ) if any part of their final product was made using RP. 
Table 2 Four point scoring system of the level of RP use in a senior design project

\begin{tabular}{|c|c|}
\hline Ranking & Description \\
\hline Zero (0) & No use of RP technologies \\
\hline Little (1) & RP technology used to test a concept \\
\hline Medium (2) & RP technology used to make a stepping stone, i.e. mold or preliminary model \\
\hline Heavy (3) & Part of the final prototype was made using RP technology \\
\hline
\end{tabular}

It is important to point out that the senior design courses are slightly different each year as historically the teaching duties have rotated among the full time faculty. Professors do, however, handoff their materials, as well as their observations on how the class went each year. Yearly department-level discussions have also allowed the class to evolve over time. It was therefore necessary to review the assignments from each year.

\section{Results}

Over the ten year span, $40 \%$ of the projects did not use RP at all. In the first seven years of projects, a majority, $54 \%$, scored a 0 , while in the last three years, $87 \%$ of the prototypes have used RP in some capacity, with $74 \%$ of groups scoring a 3. That is nearly double the amount of overall use, and over four times as much heavy use.

The assignments have been a major factor in these changes due to faculty panels and a prototype expo at which early prototypes are critiqued. The Prototype Expo began in March of 2013 and is an opportunity for design teams to gain feedback on early functional prototypes from the BME faculty and students, as well as external clinical mentors. This serves as a checkpoint on their progress. Such an expo became possible in large part due to RP technologies, as students are more able now to have a functional prototype by March.

Formal faculty panels have always been a part of the capstone and have allowed project groups to gain both formal and informal feedback. The number of panels, however, has risen from one the entire two-semester sequence in the first year to seven in the current year (2017). A major change occurred in Fall 2012, with the inclusion of themed panels. These themes in BMEG 401 are Project Options \& Resources, to help sort through potential projects; and Problem Identification \& Definition, to help teams chose a project and plan for the accomplishing it. In BMEG 402 the panels are a Spring Restart, to discuss current project status; Prototype Development, where the students and faculty evaluate the current prototype and how to develop it for the prototype expo; and Prototype Expo Feedback, to debrief on the prototype expo and 
help to iterate on the current prototypes to optimize it for the end of the semester. It is in the later panels that students often receive specific guidance on RP of their prototype and future iterations. The expo and panels are highly valuable for students as they help the teams pick a direction in iterating on their prototype, as well as forcing them to manufacture first generation ones earlier on. This was made possible because of the introduction and use of RP technologies. The assignments began about the time that the technologies began to be more readily available, and in previous years when groups were relying on machining this many checkpoints might not have been possible.

BMEG 409, a course taken prior to the senior capstone, has also changed to include a much greater focus on fabrication techniques, and in particular RP. More recent additions have included formal instruction and assignments on 3D printing and laser cutting through a project called the Cube of Knowledge. ${ }^{14}$ The project began in the Fall of 2008 with the challenge to manufacture a large 6 sided die, each side using a different manufacturing technique. Teams would design their sides in SolidWorks and then pass the drawings off to a machinist. Over time the project has changed to include laser cutting and 3D printing that students can complete on their own. The Cube challenge also now includes printing a small 3D printed object, again which can be entirely student-driven, to be placed in the middle of the cube.

The improvement in the quality of devices since RP was introduced is seen when comparing two projects from 2008 and 2015. A 2008 project was designed to improve reconstruction procedures for lyophilized drugs by twisting to allow all of the powdered drug to be mixed with a diluent before administration. Only one prototype was manufactured as it needed to be milled with the CNC router owned by the PDL, which had limited access and a queue of students waiting to use it, and could not be made from the material that was necessary for its intended usage. Upon testing, the device was found to introduce leakage to the reconstruction system. The students were not able to iterate on their design, make a new device, or try a different material. Instead, certain features and the quality of their design were sacrificed in order to match the functionality of current methods and improving the quality was stated as a future goal. The 2015 project was designed to improve the safety and visibility of transhiatal esophagectomies. The potential designs that this team came up with were similar to the 2008 project in that they were cylindrical with specific cut patterns. This team, however, was able to use a 3D printer to manufacture their device, allowing them to try multiple designs and iterate on a chosen one until it worked. This team progressed the quality their device to the point of being able to perform cadaver testing.

\section{Discussion and Conclusions}

The rising trend in RP as an educational tool can be explained by a number of key factors including the availability of machines, fluctuations in associated costs, student accessibility and training, speed of the technology, accuracy of the prototype, and introduction of RP concepts in the curriculum. The late 2000's and 2010's saw RP machines becoming more readily available, 
within the Biomedical Engineering Department, yet it was not until approximately 2013 that all factors seems to converge and lead to capstone teams choosing RP over traditional manufacturing methods. As a simple case study, a 2007 group redesigned a medical manifold to be more conical. The job was placed in a queue that was over one month long, meaning that students had little ability to iterate on their design. Furthermore, the PDL only milled out the necessary hole pattern and not the outside shape due to time restraints, leaving the final device as a cube. Had the 5-axis CNC routers or 3D printers been available at that time, the original device could have been made as designed, but again it likely would have waited in a queue. In comparison, a 2014 team designed a thumb piece to hold sensors as a part of their product with a similar necessary hole pattern and overall part shape. They were able to design and 3D print a first prototype of their device, with the proper holes and device shape, in a few days, leaving them much more time for iteration.

It is clear that rapid prototyping technology is here to stay, within education and industry. The technologies will become faster, cheaper and continue to expand in diversity. This is particularly true in biomedical engineering where we are in the early phases of biological printing. ${ }^{15} \mathrm{We}$ expect that rapid prototyping will prompt instructors to explore new assignments and pedagogical techniques, and expand what they can expect from student design teams as we have observed with this case study and aim to show other programs. For the biomedical engineering education community we feel this presents an exciting opportunity.

1. Grimm, T. (2004). User's guide to rapid prototyping. Society of Manufacturing Engineers.

2. Pham, D. T., \& Gault, R. S. (1998). A comparison of rapid prototyping technologies. International Journal of Machine Tools and Manufacture, 38(10), 1257-1287.

3. Kruth, J., Leu, M., \& Nakagawa, T. (1998). Progress in additive manufacturing and rapid prototyping. CIRP Annals-Manufacturing Technology, 47(2), 525-540.

4. Kothawade, V. E., \& Kakade, S. P. (2015). An Overview of Rapid Prototyping Methods. International Journal of Engineering Sciences \& Technology, 2(4), 1-4.

5. Petzold, R., Zeilhofer, H., \& Kalender, W. (1999). Rapid prototyping technology in medicine—basics and applications. Computerized Medical Imaging and Graphics, 23(5), 277-284.

6. Ashley, S. (1995). Rapid prototyping is coming of age. Mechanical Engineering, 117(7), 62.

7. Bryden, D. (2014). CAD and rapid prototyping for product design. Laurence King Publ.

8. Macdonald, E., Salas, R., Espalin, D., Perez, M., Aguilera, E., Muse, D., \& Wicker, R. B. (2014). 3D printing for the rapid prototyping of structural electronics. IEEE Access, 2, 234-242.

9. Newcomer, J. L., Hoekstra, N. L., Kitto, K. L., \& McKell, E. K. (2004). Using rapid prototyping to enhance manufacturing and plastics engineering technology education. Journal of Engineering Technology, 21(1), 10-15.

10. Jensen, D., Randell, C., Feland, J., \& Bowe, M. (2002). A study of rapid prototyping for use in undergraduate design education. Proceedings of the 2002 American Society for Engineering Education, Montreal, Quebec, Canada. 
11. Stamper, R. E., \& Dekker, D. L. (2000). Utilizing rapid prototyping to enhance undergraduate engineering education. Frontiers in Education Conference, 2000. FIE 2000. 30th Annual, 2 F3C/1-F3C/4 vol. 2.

12. Kim, I. Y., De Weck, O., Nadir, W., Young, P., \& Wallace, D. (2004). Innovative modern engineering design and rapid prototyping course: A rewarding CAD/CAE/CAM experience for undergraduates. Proceedings of the 2004 American Society for Engineering Education (ASEE) Annual Conference \& Exposition (Online). Salt Lake City, Utah, USA, Session, 332.

13. Tranquillo, J.V. \& Buffinton, K.W. (2015). Building an Innovation and Entrepreneurship Ecosystem at Bucknell University. Proceedings of the Spring 2015 ASEE Mid-Atlantic Conference.

14. Kennedy, E., \& Ebenstein, D. (2010). Engineering design, CAD and fabrication skills within a biomedical engineering context. American Society for Engineering Education.

15. Chia, H. N., \& Wu, B. M. (2015). Recent advances in 3D printing of biomaterials. Journal of biological engineering, 9(1), 4. 